RDA-TR-108600-003 P.1

FREE-FREE GAUNT FACTORS FOR GOLD PLASMAS AT

LASER-FI,OON CONDITIONS

FEBRUARY 1981

BY:

J. GREEN

Sponsored By:

LAWRENCE LIVERMORE LABORATORY

Post Office Box 808

Livermore, California 94550

R \& D ASSOCIATES

Post Office Box.9695

Marina del Rey,

Califernia 90291

4640 AOMIRALTY WAY - MARINA DEL REY • TELEPHONE: (213) 822-1715

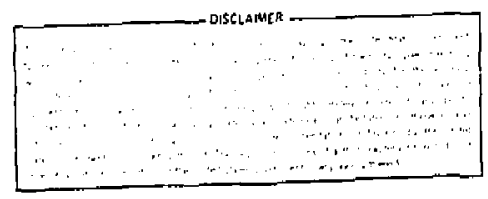


TAETE OF CONTENTS

Section

Page

I

INTRODUCTION

3

II

THE FORM OF THE CALCULATIONS

III

CALCULATIONAT RESULTS

1. The Thomas-Fermi Potentials

8

2. The Energy Dependent Values of $\left\langle\mathrm{z}^{2} \mathrm{~g}\right\rangle$

8

3. Display of $\overline{\left\langle z^{2} g\right\rangle}$, the Boltzman Average of $\left(z^{2} g\right)$

4. The Bremsstrahlung procuction Process

IV

CONCIUSIONS

REFERENCES 


\section{LISI OF FIGÜRES}

Figuxz

Page

$$
z \text { * Eo Goid }
$$

2

$z^{*}$ sos Goid

10

Effective $\left\langle z^{2} g\right\rangle$ Ior Free-Free Absorption from Gold Targets

ZfEective $\left\langle z^{2} \mathrm{~g}\right\rangle$ for Free-Free absorption Eron Go: Targets

SEfective $\left\langle z^{2} q\right\rangle$ for Free-Free Absorption From Goid Targets

äzective $\left\langle z^{2} g\right\rangle$ for Free-Free Absorption irom Goid Tarcets

Effective $\left\langle z^{2} g\right\rangle$ For Free-Froe jisorption zrom Goid Target

Effective $\left\langle z{ }^{2} g\right\rangle$ for Free-Fres sosorption from Gold Taxyets

$z$ Eective $\left\langle z^{2} g\right\rangle$ for Free-Free Ibsorgtion From Golc rangets

Effective $\left\langle z^{2} g\right\rangle$ for Eree-Eree ibsorption From Gold Targets

Boltz: an Averaga, EEfective $\overline{\left\langle z^{2} g\right\rangle}$

for Eree-Free Absorption from

Gold Targets 


\section{INTRODUCTION}

One of the dominant energy absorption processes winich convert an incident laser beam into themal energy is the "free-free abscrption" of the laser radiation. Convarsely, very high energy electrons (called supez-thermals) in any laser target will emit high-energy Bremsitrahlung, ard it is common practjce to attempt to estimate the super-thermal population by examining the Bremsstrahlung spectrum. Clearly, it is important to have a precise understanaing of the accuracy of any estinates of the free-free Gaunt factor which may be enbedded in the codes that follow the physics of laser interactions.

At present, it is common practice either to treat the Iree-Eree absorption in the Born approximation, or to treat the ionic scattering potential as a coulomb or a screened Coulonb potential. The Born aporoximation solution to freefree scattering in the screened Coulomb potential is trivial; the exas solution to the Coulomb problem has been known for some time (ReE. 1).

In a dense plasma, however, the scattering potential is not a Coulomb potential; rathez it is a self-consistent atomic potertial with some aporooriate boundary concition. Furthermore, for many values of photon and electron energies, the Born approximation is grossly inadecuate. For these reasons, we hate attempted a precise theoretical comotation of the Iree-Erse Gaunt factor in gold glasmas.

Fortunately, we solution to the problem in a general central potential (for given electron and gnoton energies) has been worked out elsewhere (Ref. 2). A code exis zs which permits the calculation of the required wave functions anc matrix elements for such a potential. However, previously, 
calculations have been made only for the screened Coulomb potential (Ref. 3).

To address the problem at hand, we mocel the ionic gold scattering centers by thei: Thomas-Fermi temperature-depencent potertial (Ref, 4), We use the Brem IV code (Ref, 3) to calculate the free-free Gaunt factors in that potential. As aiscussed in the concluding section, this provides us with a clear-cut and pracise answer for some stecial cases, and a general aporoximation algorithm whose precision can be estimatea. 


\section{THE FORA OF THE CALCULATIONS}

The theory and the siructire ci the 3rem Iy code hate bes: discussed eisewhere (Ref. 3). Fowever, sor converience ve have reprocuced the urcertinc equations.

The absorption cross section per unit electron carsity is

$$
a=\frac{\left\langle z^{2} g\left(k_{i}, v\right)\right\rangle i e^{6}}{3 \sqrt{3} i=m^{2} y^{3}} \mathrm{~cm}
$$

where

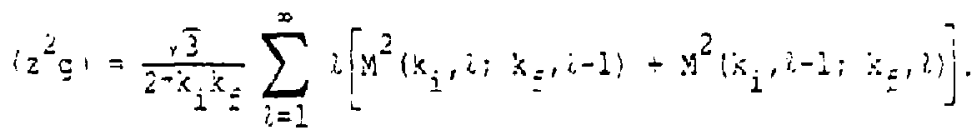

äere

$$
E_{i}=k_{i}^{2}=\frac{\pi v^{2} a_{0}}{e^{2}}
$$

is tre energy of tide absorbing electron measured in zydicergs, and

$$
\Sigma_{E}=x_{z}^{2}=x_{i}^{2}-i
$$

is the energy tre electron has atter absorbing a photon whose energy is a Rydbergs.

The sum in Equation (2) is a sur over a partial ivave expansion of angular momention $x$. The M's are matrix elemen:s of Eree wave function $\psi h, k(r)$ of angular momentum $h$, anc 
enercy $k^{2}$ moring on a central sotential $\forall(r)$. The wave junctions satisf the following equaton, where $=$ is in units ot a the 3oin = acius.

$$
\begin{gathered}
\psi_{2, k}(r)=\left|\frac{2(i+I)}{z^{2}}-7(r)-k^{2}\right| \psi_{2, k}(r) \\
\quad \lim _{r+\infty} j_{i, k}+\sin \left(k_{z}=-\frac{2 \pi}{2}+z_{i}\right) .
\end{gathered}
$$

The: are the "exact" Eree wive Eunctions.

The potential $v(r)$ is the scattering potential; in our sase, $\because ?$ is taken to je the temperature-cepercent ThomasFan: gotential. Its calculaticr is described ing. 4h. The potential $\ddot{y}(z)$ must satisy the conaitior.

$$
\lim _{r \rightarrow 0} y(r) \sim \frac{2 z}{r} \text { Rqüberss. }
$$

The natrix eiements are the acceleration matrix elements subject to the selection rule $i l=z$.

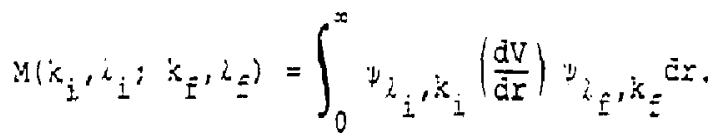

The jrem IV code integrares Eguazior (5), Esums $\mathrm{X}$ according =0 Ectazion (7), and finalif Eorms the sum is Eauation (2) and akes $\left\langle z^{2} g\right\rangle$ availeble. The phase shifts $i_{i}$ are aiso obtaized, but are not reported here. In principle, the rumber of parriaj waves reguired for convergence increases rapicly with $k$. Zowever, a calchlational cevice described eisewhere (Rez. 3) makes convergence at high energies a tractable groslem. 
For completeness, 3 rem iV also grodices the $\left\langle 2^{2} g\right\rangle_{3^{\prime}}$ tife value of $\left\langle z^{2} g\right\rangle$ in the Born aporoximaticn. It $i s$ well know. (Bef. 6) that

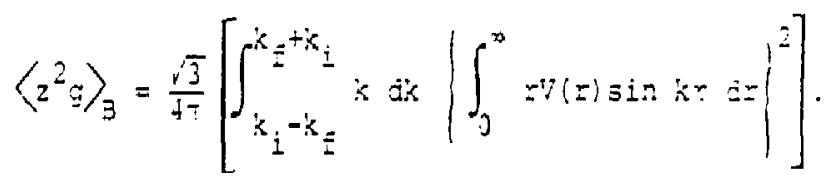

If: the case of the Thomas-Fermi potential, the results yuoted in the remaincer of this report show large differences between $\left\langle z^{2} g\right\rangle$ and $\left\langle z^{2} g\right\rangle_{B}$ for many regions of interest for laser experiments. 


\section{TLE TECNAS-EEXNT POTENTEALS}

If we use: the Thomas-Fermi mocel, each separate value of temperature and density for the gold plasme will yisid a aiszerent potential $\eta(r)$. In orjer to examine $\left\langle z^{2} \xi\right\rangle$, we chose piasma temperatures of $\mathrm{kT}=100,250,500$, and 1000 e at densizies $0=0.01$ and $1.0 \mathrm{gn} / \mathrm{cc}$, and computed $v(r)$ Eor each c: these temperature-density states (Rez. 4).

II we choose to write the potential in the form

$$
V(I)=2 Z^{*} / L
$$

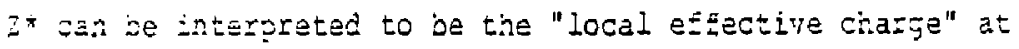
any gosition $x$. According so Equation (6)

$$
z^{*}(0)=2 \text {, the nuclear charge. }
$$

In Zzzures 1 anc 2 we exhibit $z^{*}(f)$ Jor two tyoicai tenzerature-density zoints. Distances are measurec in units 0 三 30i: r $\exists$ cii. The precise calculational scheme for computiog we Thomas-remi potential for any particular $T, a$ point is aiscussed in cetaii elsewhere (Ref. j).

2. TEE ENERGY-DEPENDENT VAIUES OF $\left\langle z^{2} \mathrm{~g}\right\rangle$

The effective charge tines the Gaunt fuctnr $\left\langle z^{2} y\right\rangle$ depends on $\Xi_{i}$, the energy of the absoring electzon, as well as on $\triangle$ the photon energy, and $V(r)$, the scattering gotential. In Figures 3 thrcugh 10 , we exhibit the values of $\left\langle 2^{2}\right.$ g $\rangle$ as a zunczicn of $E_{i} / k T$. Separate sets of calculations are macie for the sifzerent $v(r)$ 's corresponding to gola plasmas at various $z, \pi$ points of interest. The photon energy corresponds to the iaser wavelengths of $i=1.06 \mathrm{~cm}$. These energy-cependent 


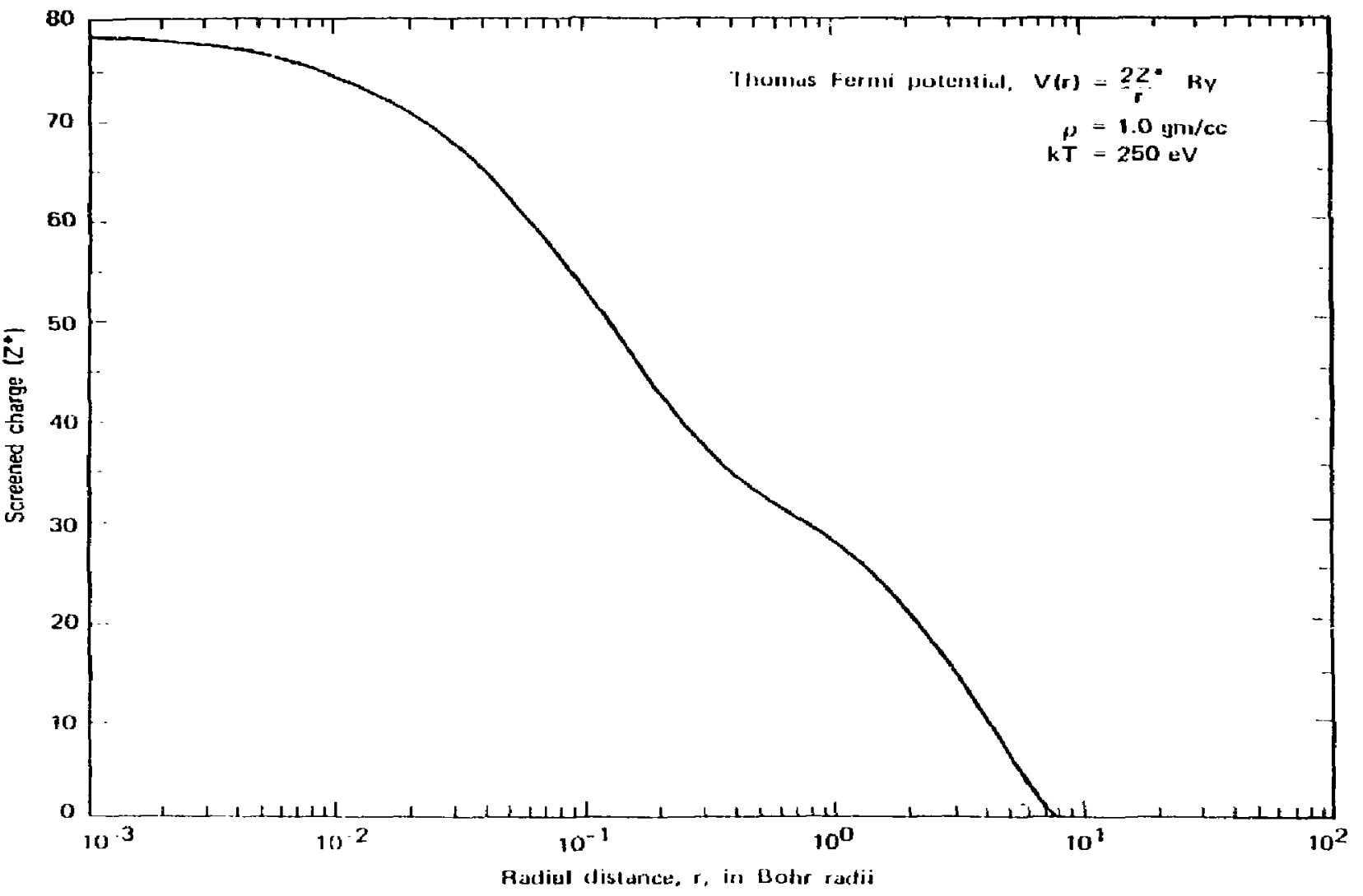

ligure: 1. L* tor hisld 


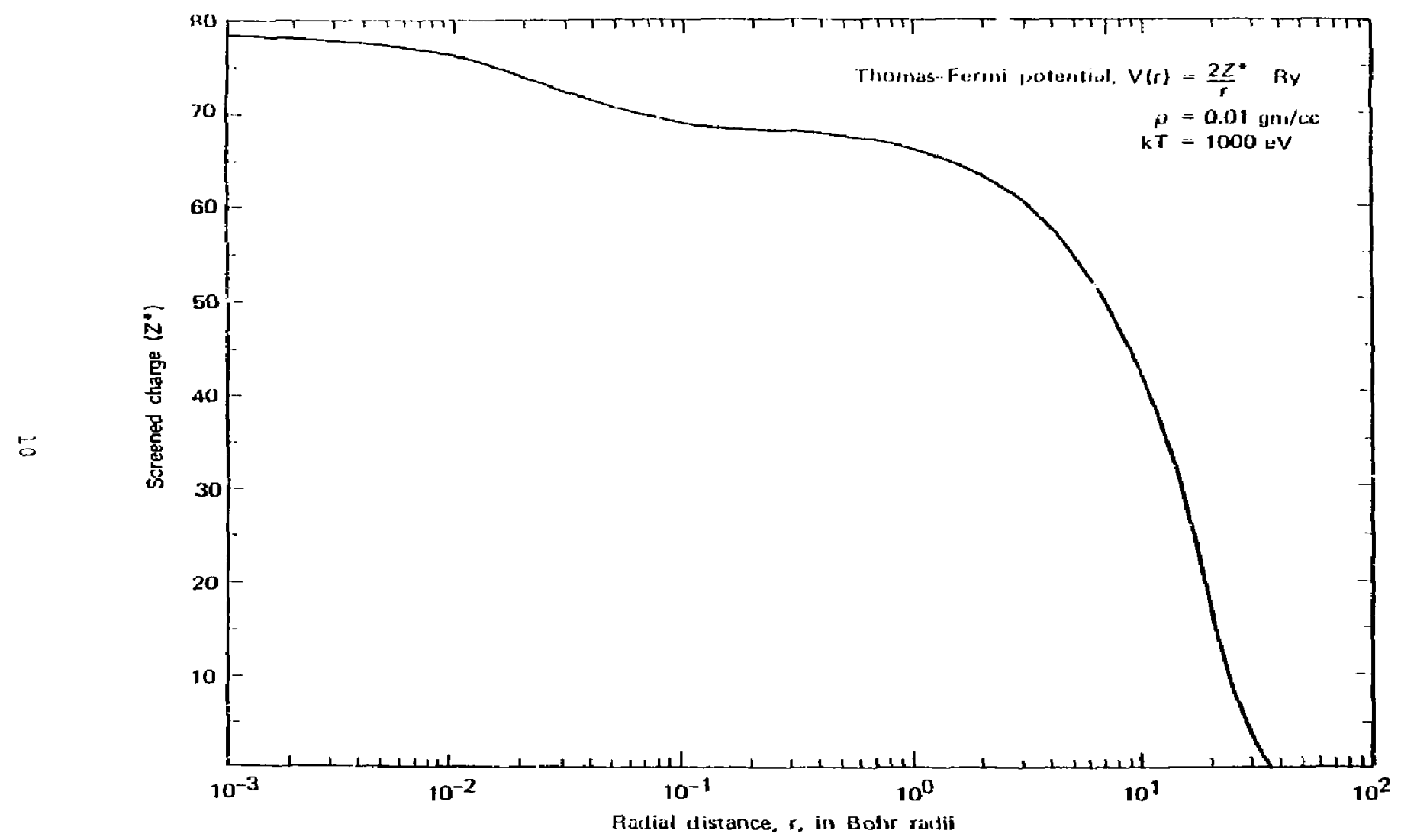

Figure 2. $Z^{\star}$ for liold 


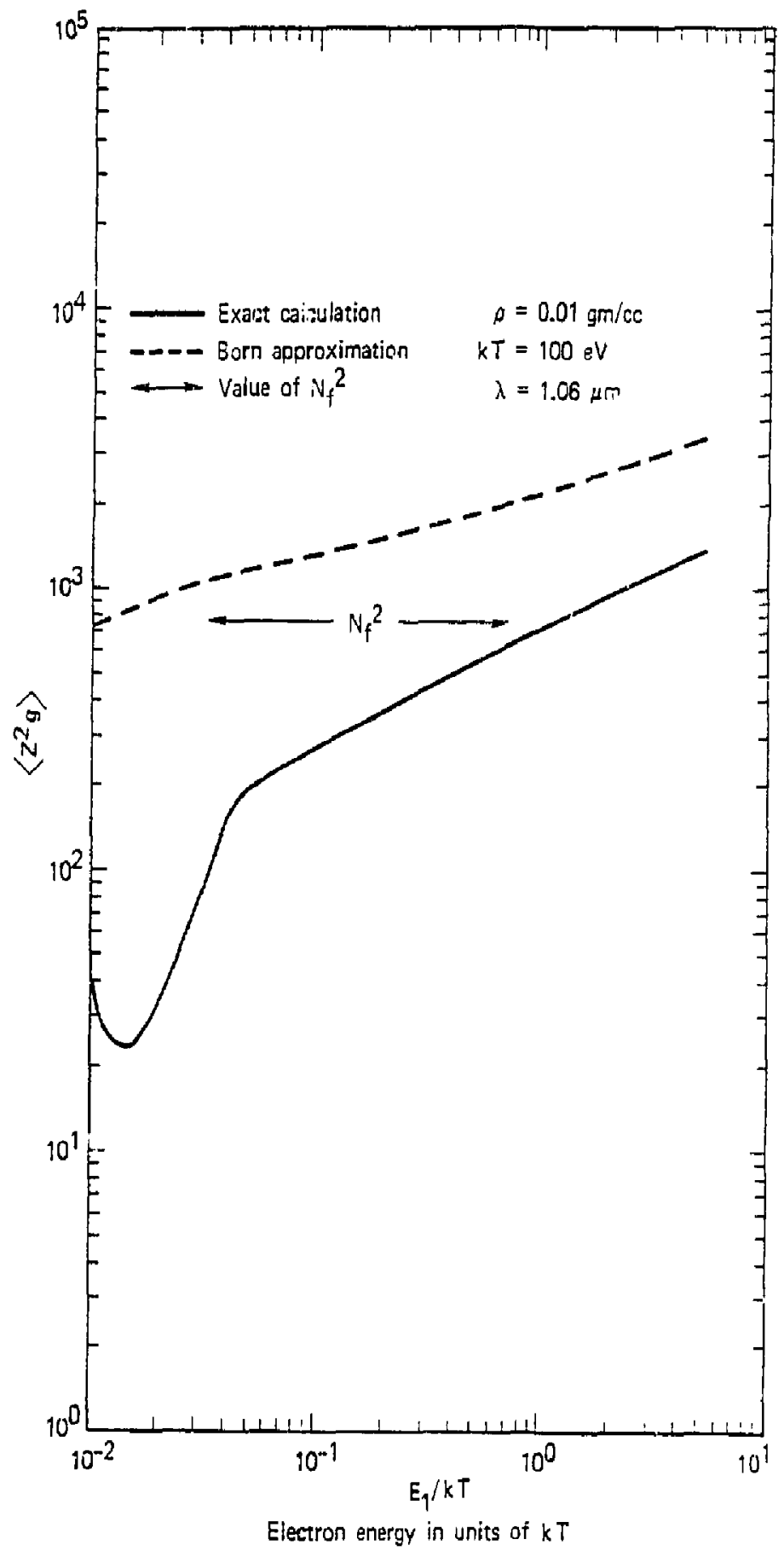

Figure 3. Effective $\left\langle z^{2} g\right\rangle$ for Free-Free Absorption from Gold Targets

II 


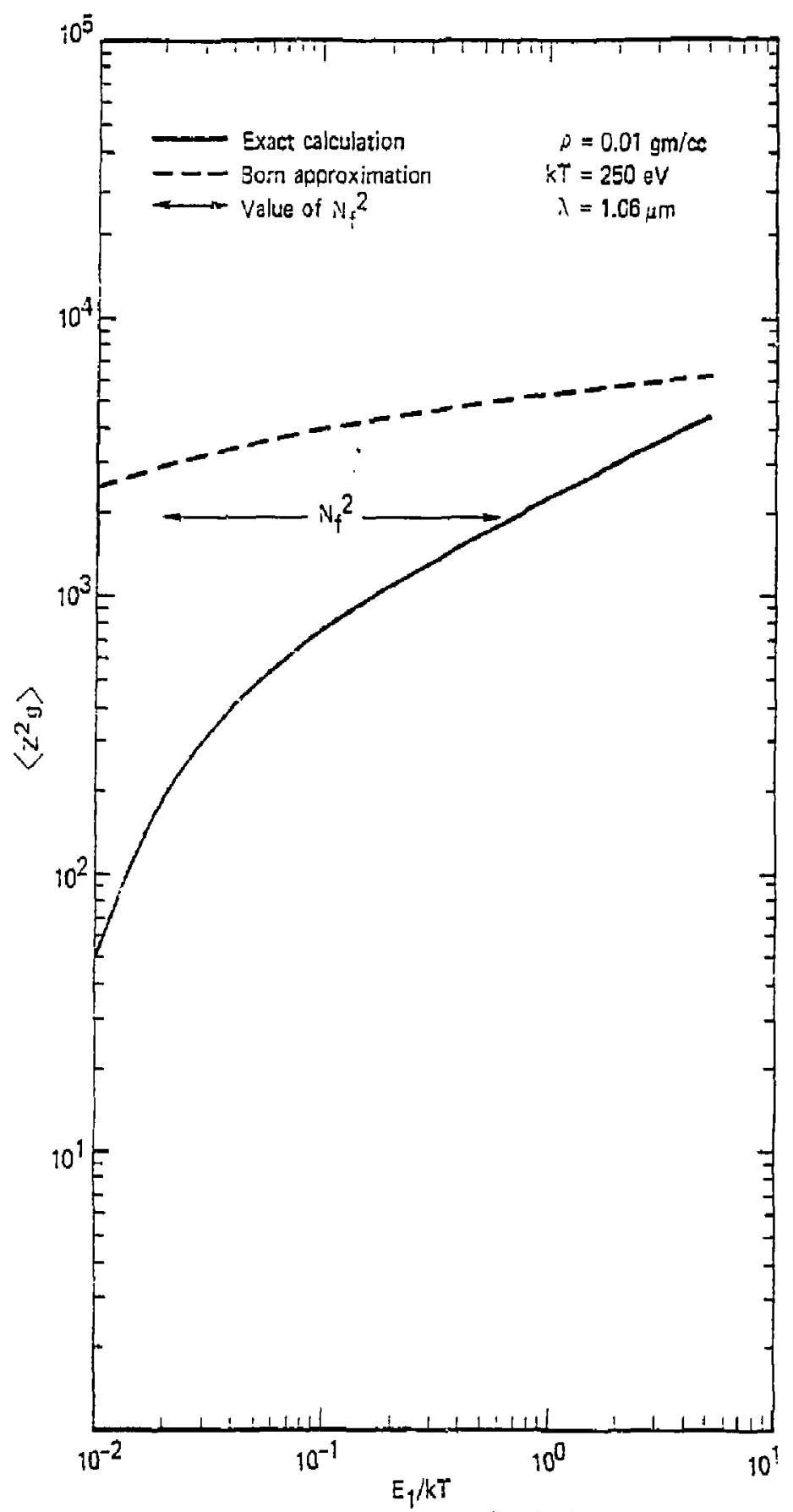

Electron energy in units of $k T$

Figure 4, Eifactive $\left\langle Z^{2} g\right\rangle$ icr Free-Free Absorption from fold Targets 


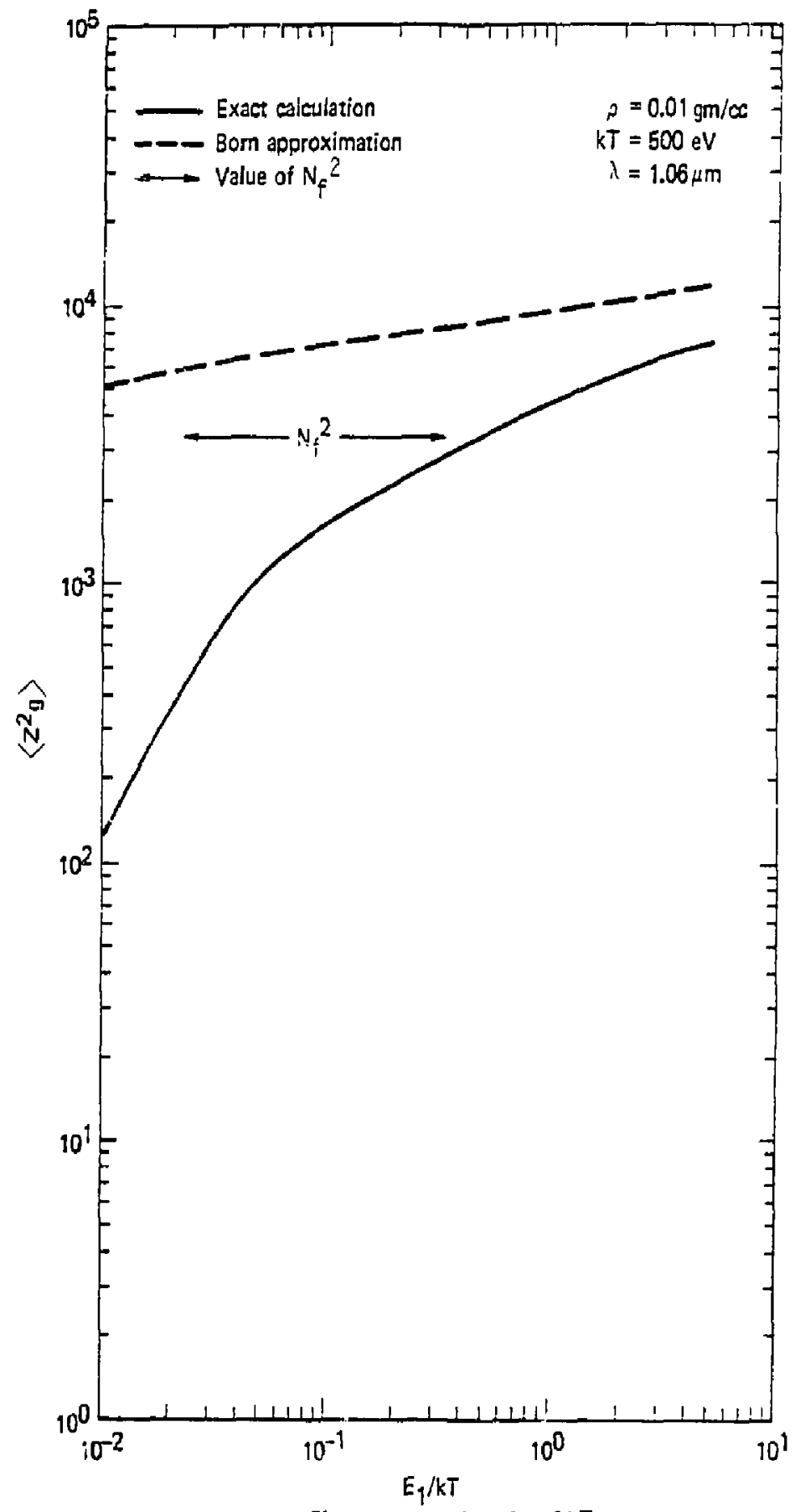

Electron energy in units of $\mathrm{kT}$

Figure 5. Effective $\left\langle\mathrm{Z}^{2} \mathrm{~g}\right\rangle$ for Frea-Free Absorption from Gold Targets 


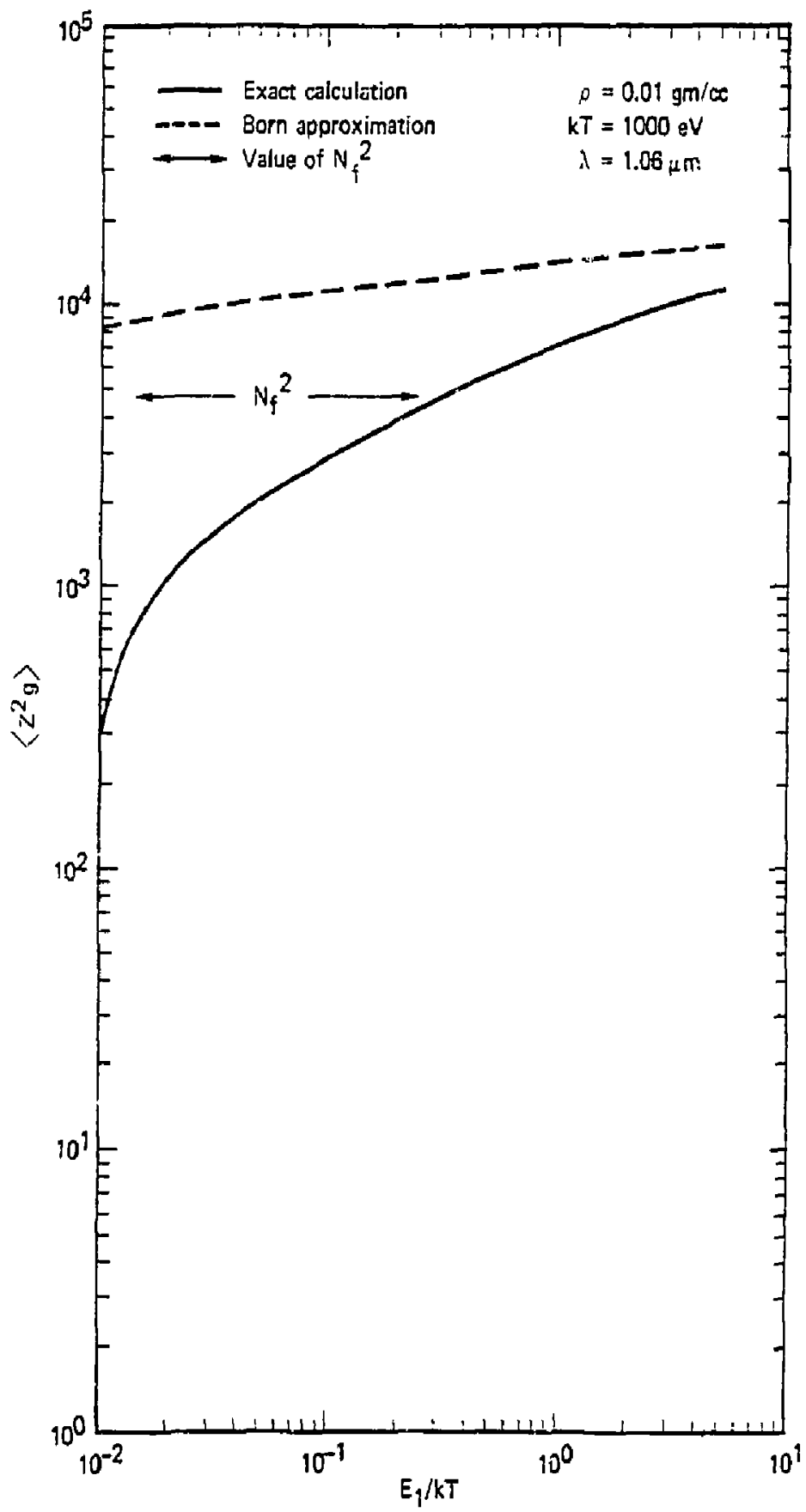

Electron energy in units of $k T$

Figure 6. Effective $\left\langle z^{2} g\right\rangle$ for Free-Free Absorption from Gold Targets 


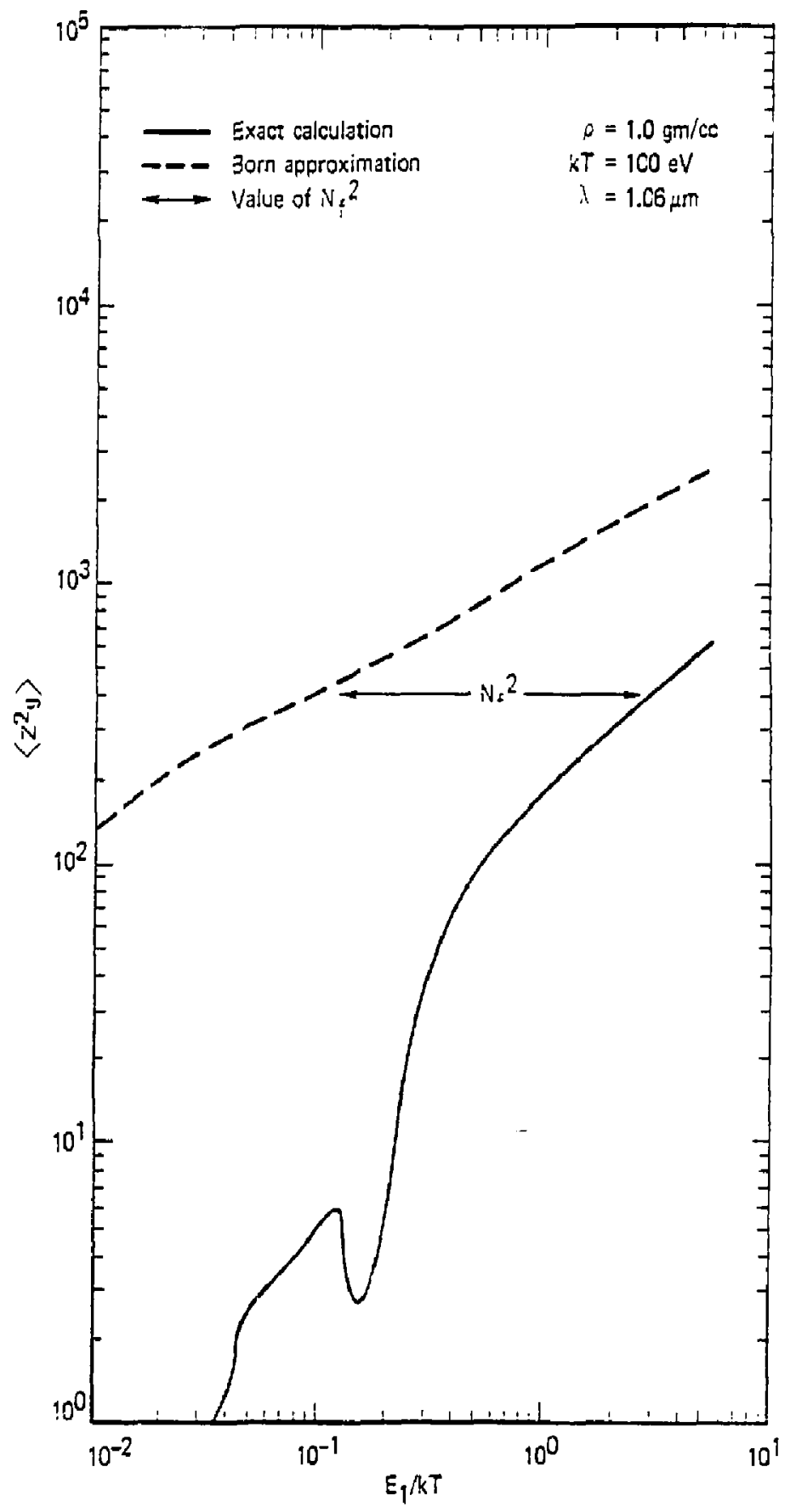

Stectron energy in units of $k T$

Figure 7. Eitecive $\left\langle z^{2} j\right\rangle$ for Frea-Fres dibsorgtion from Eold iargets 


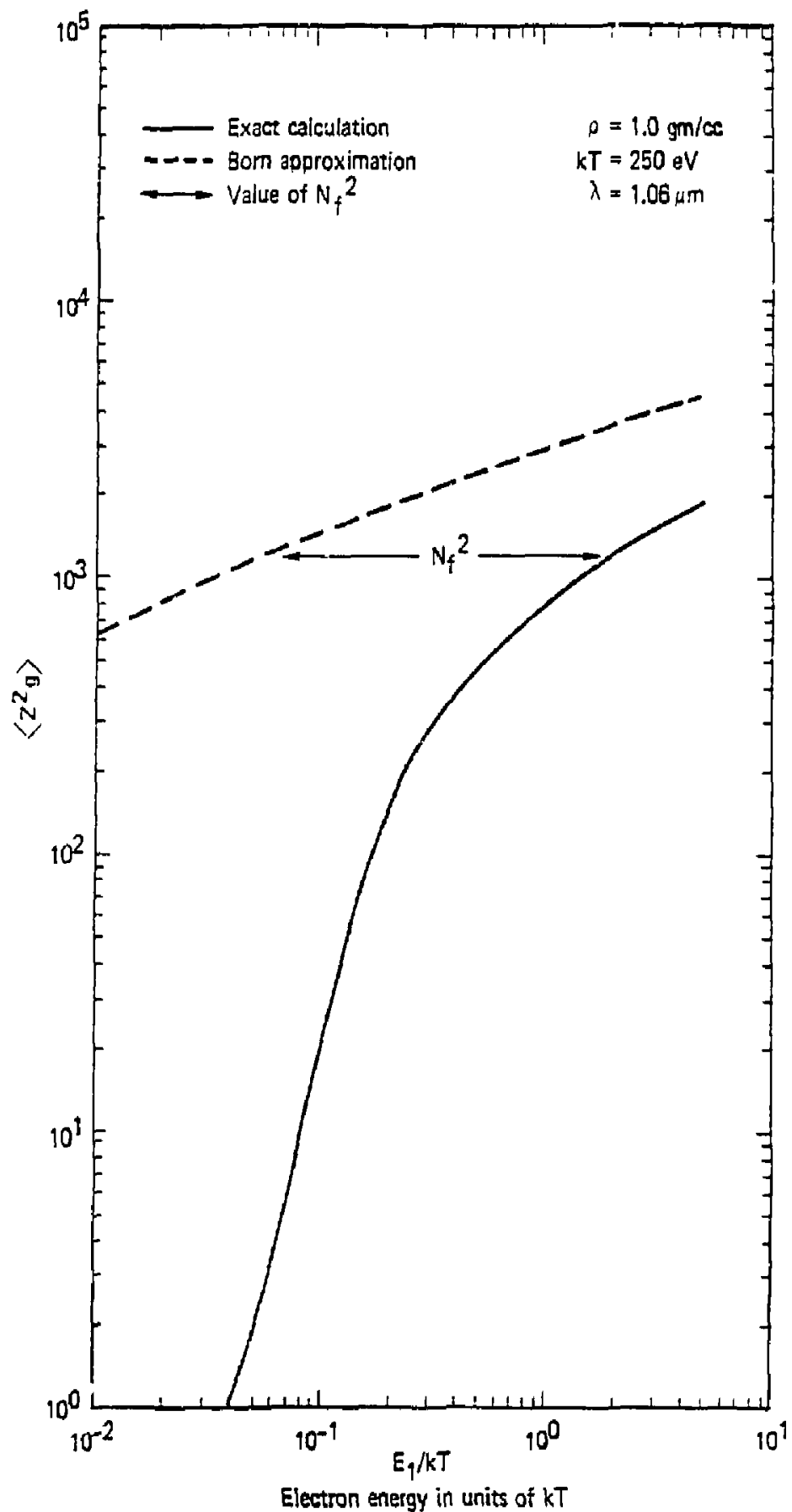

Figure 8. Effective $\left\langle Z^{2} g\right\rangle$ for Free-Free Absorption from Gold Targets 


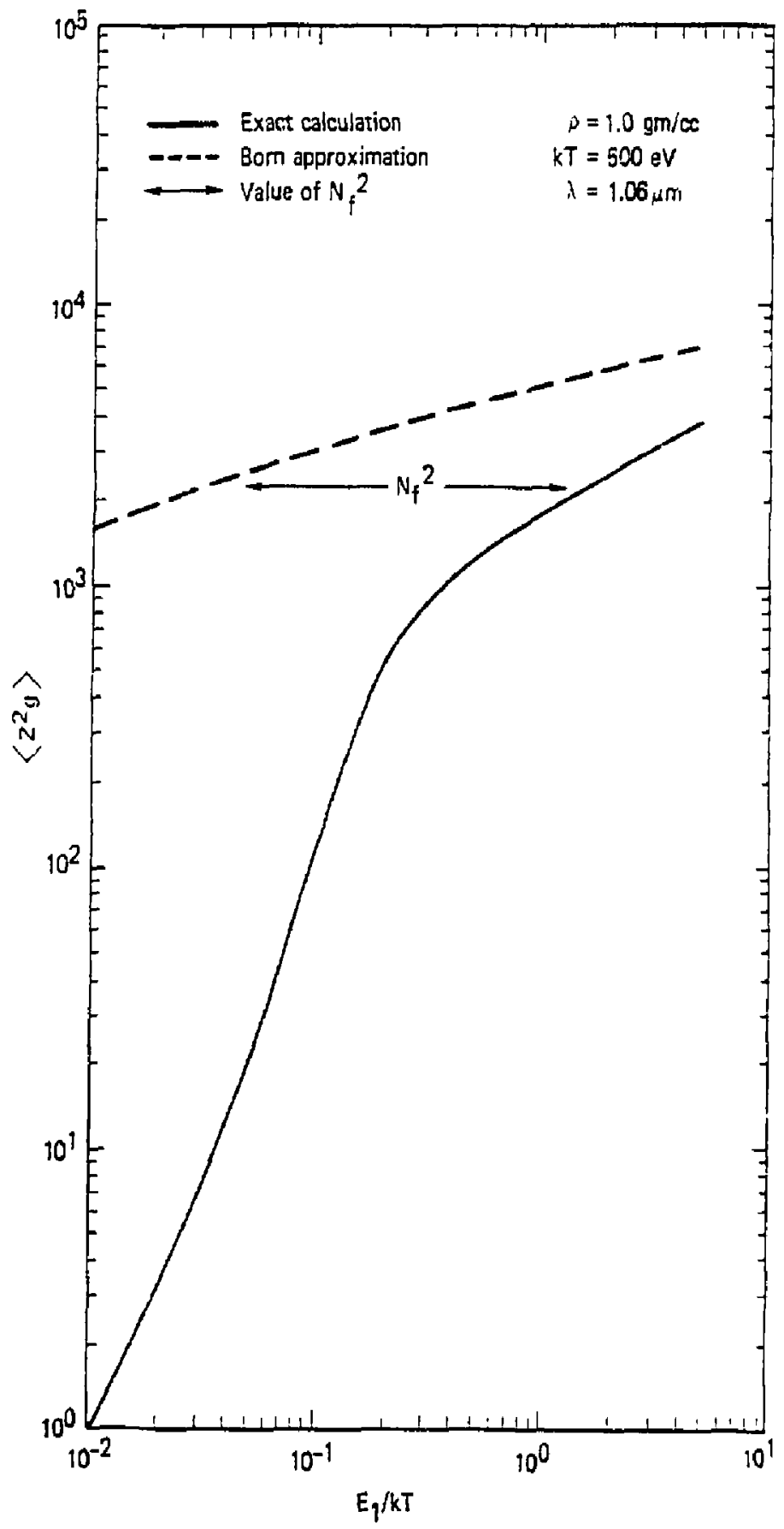

Electron energy in units of $k T$

Figure 9. Effective $\left\langle z^{2} q\right\rangle$ for Free-Free Absorption from Gold Targets 


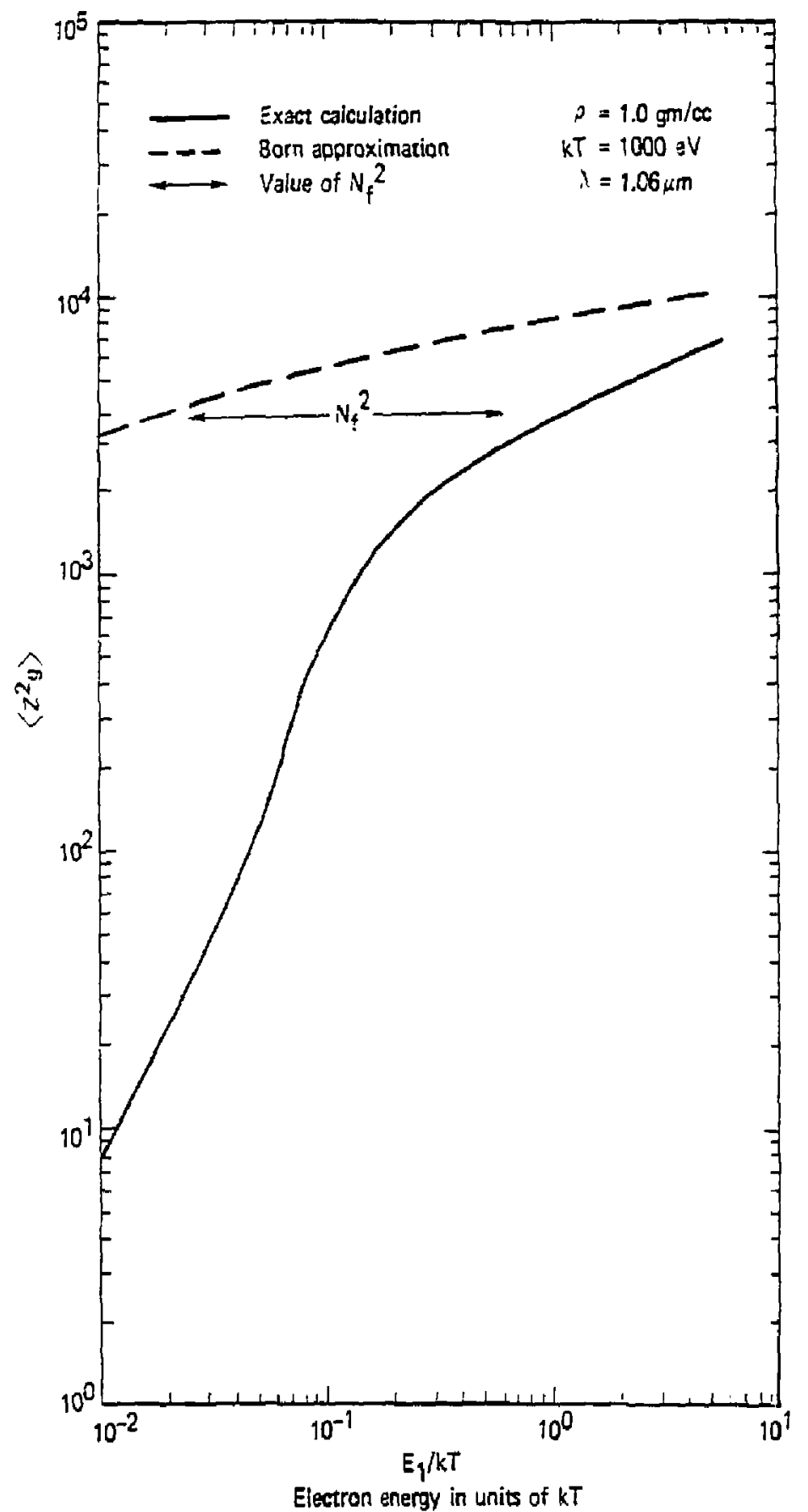

Figure 10. Effective $\left\langle 2^{2} g\right\rangle$ for Free-Free Absorption ir .. wid Targets 
values $0:\left\langle z^{2} g\right\rangle$ can be areaged against any existing elsctr:x. cistribution.

For comparison we aiso exhijit $\left\langle z^{2} g\right\rangle_{3}$, the sorn approximation value of $\left\langle 2^{2} g\right\rangle$. This quantity is computed using Eutztion ( $a$; and the corresonding Thomas-Ferm: potential. At low energies, the Born approximation resule is in erzor $\vdots y$ is much as an orcer of magnitude. For the Thomas-zermi pocentiz!, the 3orn aporoximation is not reliable for electron energies such tiac $\Sigma_{i} \leq 2^{2}$ Rydbergs.

in the Thonas-zermi theor $i$ we can extuet $\equiv$ value for $X_{i}$ the numer of free eisctrons (Ref. b). We do this by using

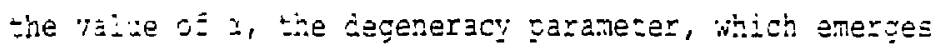
altchiatica: $\because \because$ whenerer $\because\{r)$ is calculated for a giren $a, z$ goizt.

I: the Gaunt Eacoor were ijentically ecual to urity, and if the Thomas-Fermi potansiai benaved as if it scattered like $2 \mathrm{~N}_{\mathrm{L}} / \mathrm{r}$, then $\left\langle\mathrm{z}^{2} \mathrm{~g}\right\rangle$ woula equal $\mathrm{N}_{\mathrm{f}}^{2}$.

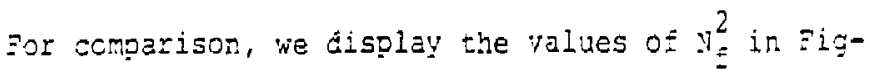
uxes $i$ through 30 . It is interesting to observe tiat in the region $\Xi_{i} \approx \mathrm{kT},\left\langle z^{2} \mathrm{~g}\right\rangle, \mathrm{N}_{i}^{2}$.

3. DISPEAY OF $\overline{\left\langle z^{2} g\right.}$, THE 30TTMMN AVERAGE OF $\left\langle z^{2} g\right\rangle$

we compute

$$
\left.\overline{\left\langle z^{2} g\right\rangle}=\int\left\langle z_{g}^{2}\right\rangle e^{-E_{i} / K_{T}} \hat{c}_{i} \Xi_{i} / k_{T}\right\rangle
$$

which is the proper Boltzman average of $\left\langle z^{2} g\right\rangle$. in examinaticn of Equation (1) shows that Equation (11) gives the proper weighting provided we say 


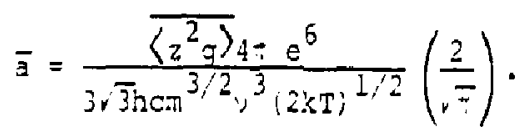

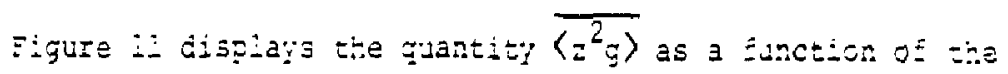
piasma zemper ture, kn. Calculatiors have been cone for zo jensities. Ine zesulis of giqure 11 can be used directiy in

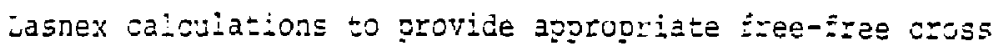
sections Ex the assorption of iaser zaciation in a gois ?ㄴ. $35 \pi$.

Alternatively we may seek a genera: algoritim which might je generaily zpolicable. In Table $i$ we compare values of $\left\langle\mathrm{z}^{2} \mathrm{~g}\right\rangle$ itith the corresponding yalues of $\mathrm{v}_{z}^{2}$. Foz $z=0.0 \mathrm{I}$, $\mathrm{v}^{2}$ is an excellent approximation to $\left\langle\mathrm{z}^{2} \mathrm{~g}\right\rangle$. it $==1, \mathrm{v}_{z}^{2}$ coes

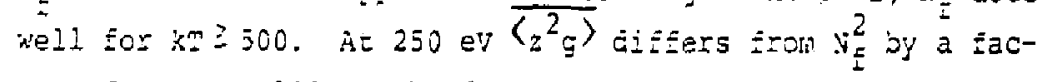
tor of two; at $100 \mathrm{eV}$ the factor is three. Certziniy Table i gives a alear picture of the precision wath wich $\left\langle z{ }^{2}\right\rangle^{\prime}$ máz be replaced by $\mathrm{N}_{z}^{2}$.

$\therefore$ THE SREMSSTRAETLNG ZRODCCTION

The calculation of $\left\langle z^{2} g\right\rangle$ sor 3remsstraniznc production jresents a dizferent picture than that described 1 . Sections 2 and 3 . The Bremsstrahlung radiation is jroduced by super-thermal electrons whose energies far exceed the average electron energy in the plasma. These very high energy eleczrons are capable of penetrating deep into the interior of the ion and sense an electric field which is much higrer than that inolied by ion of average charge $v_{f}$.

Table 2 shows the results of detailed calculation of the efEective $\left\langle{ }_{2}{ }^{2} g\right\rangle$ a ising from super-tinermals whose energies are as large as $110 \mathrm{kev.} \mathrm{We} \mathrm{ccmpare}\left\langle z^{2} g\right\rangle$ with $v_{\equiv}^{2}$ Eor gold ?iasmas $a=100 \mathrm{ev}$ and $1000 \mathrm{ev}$, respectively. 


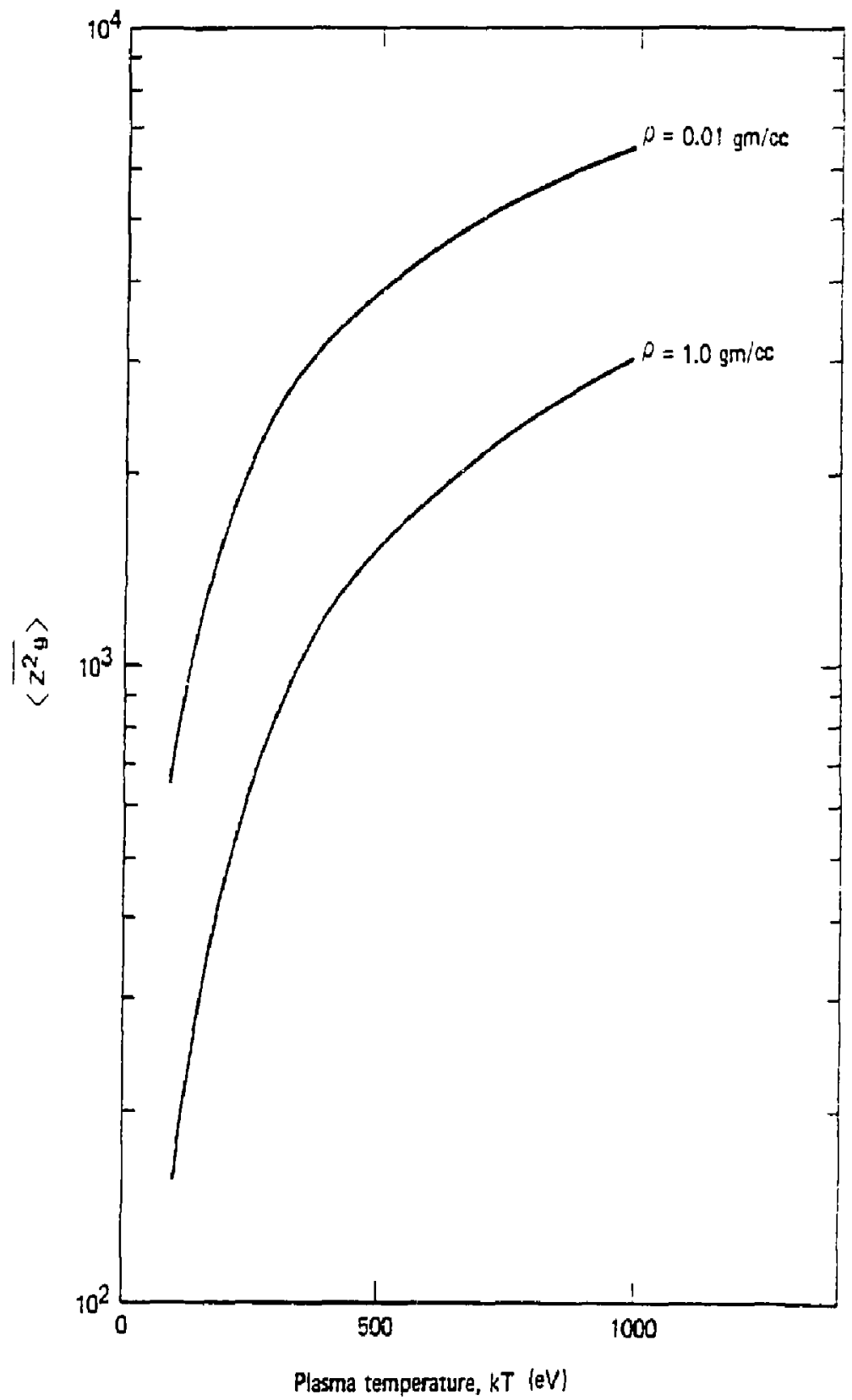

Figure 11. 3olizman Average, Effactive $\left\langle\overline{z^{2}}\right\rangle$ for Free-Fres ibsorotion from Goid Targets 


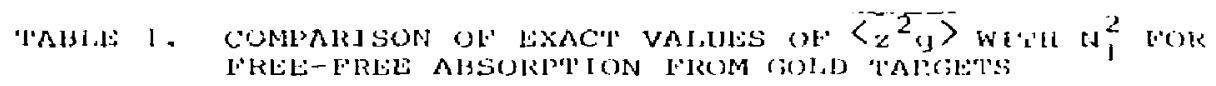

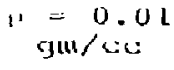

\begin{tabular}{c|c|c|}
\hline $\begin{array}{c}\mathrm{k} J \\
(\mathrm{eV})\end{array}$ & $\overline{\left\langle z^{2}{ }^{2}\right\rangle}$ & $\mathrm{N}_{\mathrm{L}}^{2}$ \\
\hline 100 & $6.54 \times 10^{2}$ & $7.6 .3 \times 10^{2}$ \\
250 & $2.0 .1 \times 10^{3}$ & $1.97 \times 10^{3}$ \\
500 & $3.818 \times 10^{3}$ & $3.37 \times 10^{3}$ \\
1000 & $6.43 \times 10^{3}$ & $4.76 \times 10^{3}$ \\
\hline
\end{tabular}

$$
\text { "yin/ces" }
$$

\begin{tabular}{|c|c|c|}
\hline $\begin{array}{c}\mathrm{k}^{\prime} \mathrm{l} \\
(\mathrm{eV})\end{array}$ & $\overline{\left\langle\mathrm{z}^{2} \mathrm{u}^{\prime}\right\rangle}$ & $\mathrm{H}_{\mathrm{f}}^{2}$ \\
\hline 100 & $1.57 \times 10^{2}$ & $1.19 \times 10^{2}$ \\
250 & $6.27 \times 10^{2}$ & $1.16 \times 10^{3}$ \\
500 & $1.49 \times 10^{3}$ & $2.26 \times 10^{3}$ \\
1000 & $3.06 \times 10^{3}$ & $3.76 \times 10^{3}$ \\
\hline
\end{tabular}




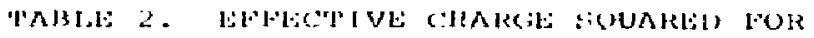

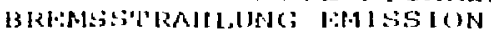

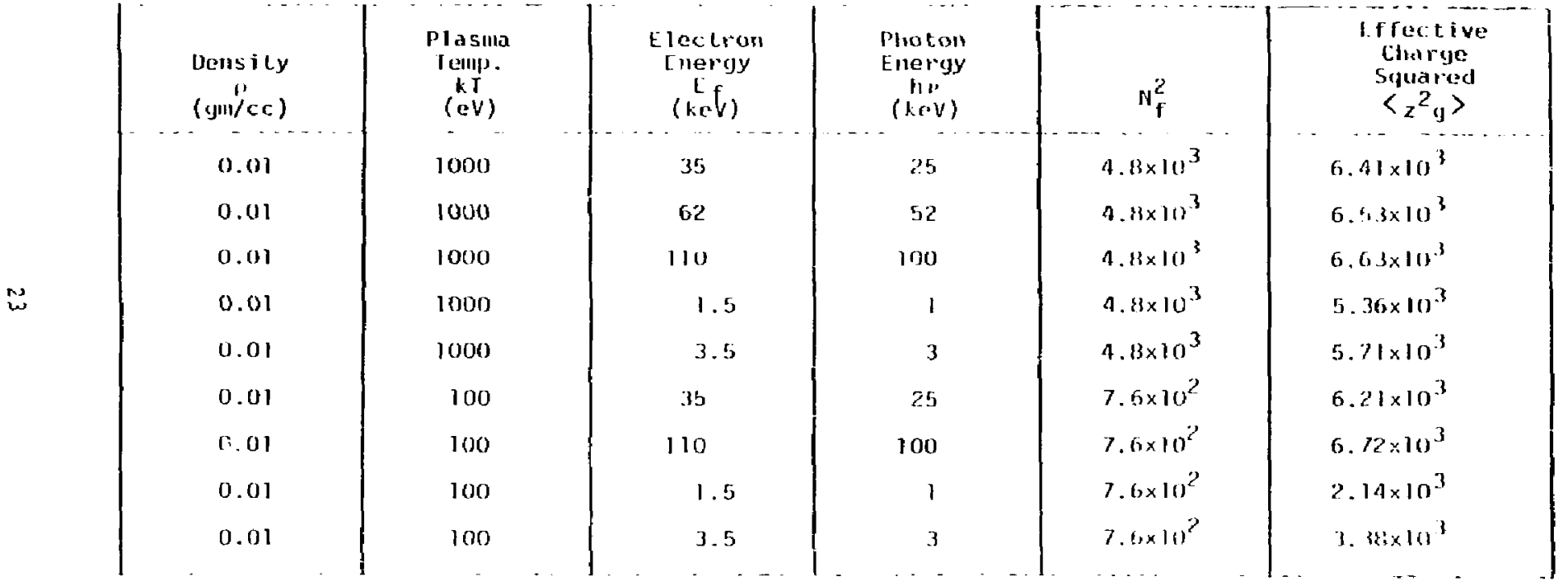


It is clear that for super-thermals there is little connection between $\left\langle z^{2} \Rightarrow\right.$ and $x_{\hat{O}}^{2}$. Furthermore, for the high energy spestrun ( $\mathrm{k} ;-25 \mathrm{ke}$ i) the super-thernals penetrate so beeply into the ionic potertial that one can, in eztect, apprcximate $\left\langle z^{2} \Rightarrow\right.$ by $z_{0}^{2}=(79)^{2}=6.24^{3}$, the square of the ricieaz cherge. 


\section{I\%. CONCLUSIONS}

We have mace careful arci cetailed caiculations o: tae Eree-free absorption process for electrons traveling in tie region of the temperature-dependent Thomas-Fera potentiai of various golc plasmas. The Born approximations jolied into this potential give a poor representation oi the crosi section; we can nevertheless make some very simpie stataments about aigorithns for use in the calcuiational codes.

1. The Boitzman averaçes value $\overline{\left(z^{2} g\right)}$ used to compute the absorption of laser radiation can be replaced by $\mathrm{v}^{2}$, when $\mathrm{v}_{f}$ is the nimber of Eree electrons per aton present in the plasna.

2. The effective charge $\left\langle z^{2} g\right\rangle$ used to compute 3remsstrahlung emission From super-thermais can ie roplaced by $z_{0}^{2}$, the square of tie r.tuciear charge. For photons whose energy, h: $\geq 25 \mathrm{keV}$, the erzor is less than 5 percen:.

3. It is incorrect to replace $\left\langle z^{2} g\right\rangle$ hy $v_{E}^{2}$ in estimating Bremsstranlung emission by super-themals. 


\section{REFERENCES}

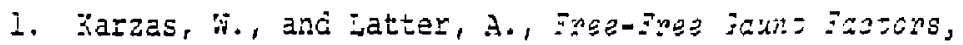
Ranä Corp., PVi-20:0-AEC, November 1957.

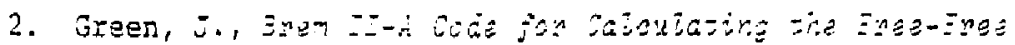

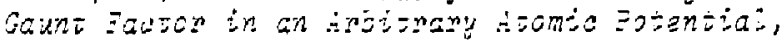
$\Omega \&$ L Associates, RDA-TR-237-AEC, Jure 1973.

3. Green, J., in tooupata Catoutition ot ine Senened

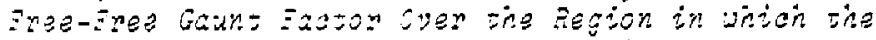
Jom Spyozimazisn Ezija, R \& D Associates, RDA-TR-4900-002, December 1973.

4. Latter, R., Equation of Staze on the rhomas-zenmi Hoaji, Ean= I, Ranc Corp., RM-1227, Apris i954.

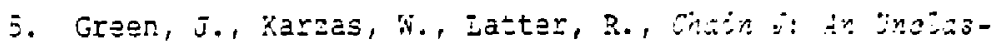

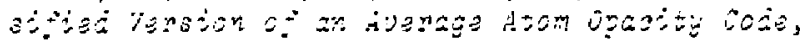
R $\mathrm{D}$ Associates, RDA-TR-4900-005, iugust 1974.

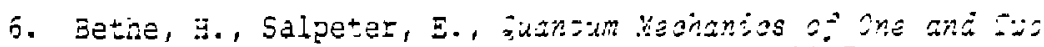

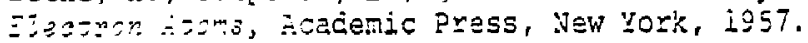

